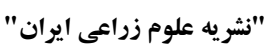

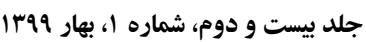

اثر بيمارى زنك زرد بر ويزگى هاى زراعى و فيزيولوزيكى ارقام بينابين و زمستانه

مقاله بثزوهشى

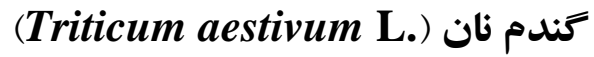

Effect of yellow rust disease on agronomic and physiological characteristics

of winter and facultative bread wheat (Triticum aestivum L.) cultivars

$$
\text { محمد رضايى مر اداعلى '، علير ضا عيوضى بّ و شهر ام شيرعليز اده }
$$

جكيده

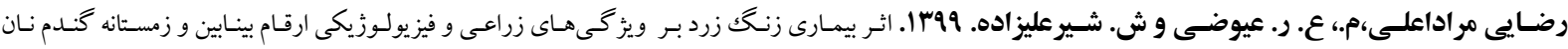

(Triticum aestivum L.)

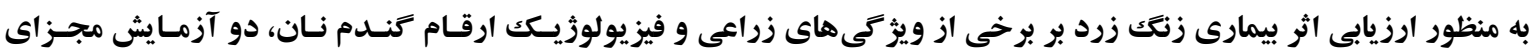

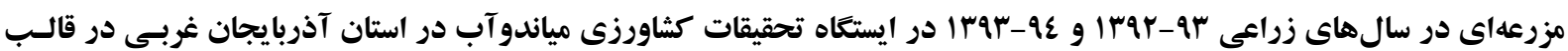

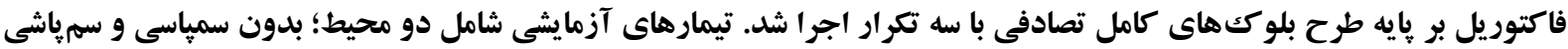

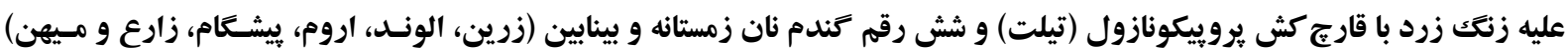

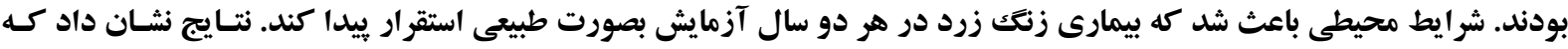

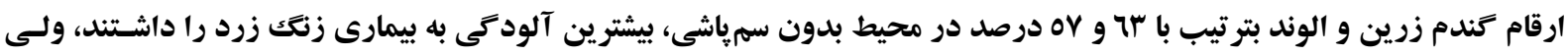

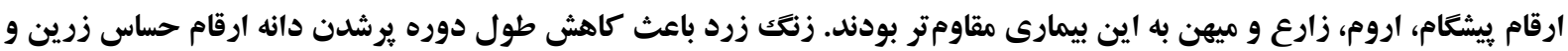

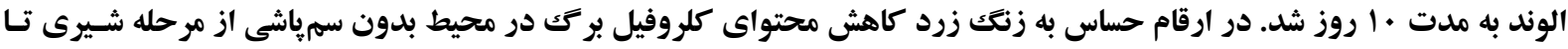

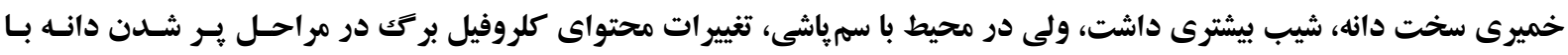

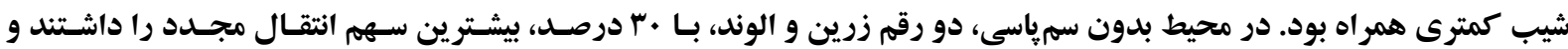

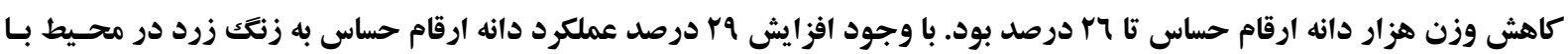

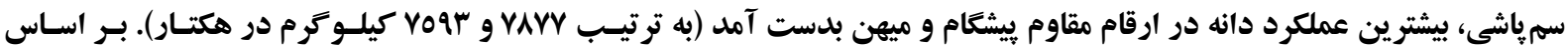

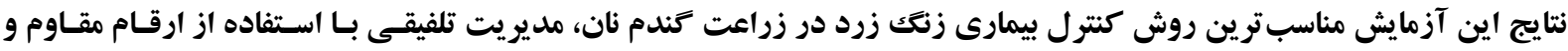

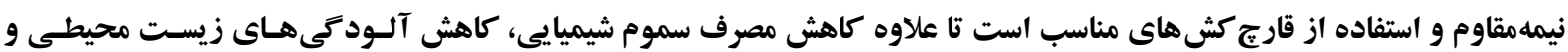
كاهش هزينه هاى توليد نيز عايد شود.

وازههاى كليدى: انتقال مجدد، تنش زيستى، قارج كش، مديريت تلفيقى بيمارى و كندم نان.

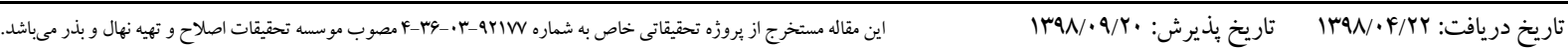

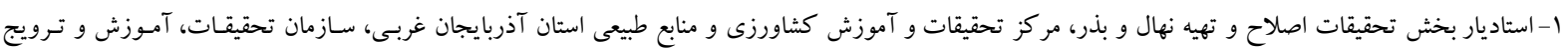
كثاورزى، اروميه، ايران (مكاتبه كنده) (يست الكترونيك: Hezaei54@yahoo.com

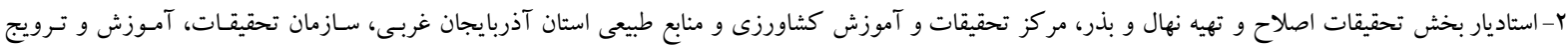
كثاورزى، اروميه، ايران r- مربى ثزوهش بخش تحقيقات اصلاح و تهيه نهال و بذر، مركز تحقيقات و آموزش كثاورزى و منابع طبيعى استان آذربايجان غربى، سازمان تحقيقات، آموزش و ترويج كشاورزى، اروميه، ايران
} 
(Afshari, 2000; زنـگك زرد معرفى شـده بودنـــ

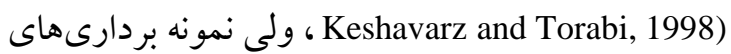
انجام شده نشان داد كه هيجِكـدام از ارقـام ذكـر شـــه،

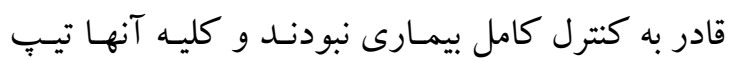

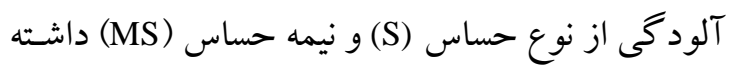

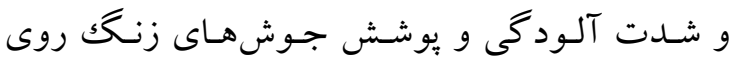

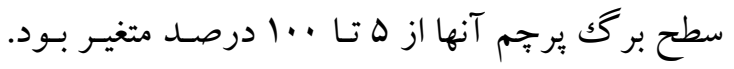

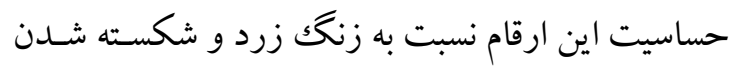

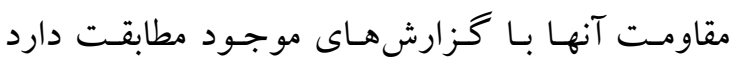
Afshari et al., 2010; Nazari et al., 2000)

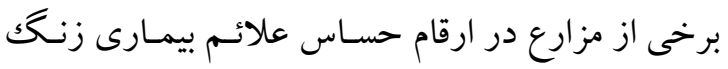

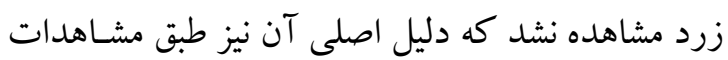

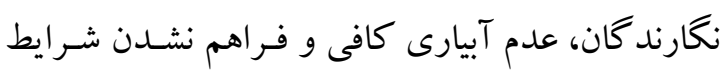

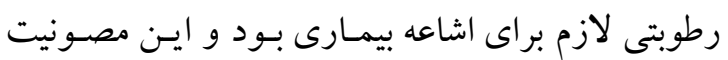

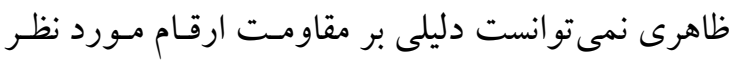
باشـــ. آكريـوس (Agrios, 2004) و ترابس و همكـاران نيز در خصـوص شـرايط مسـاعد (Torabi et al., 1995)

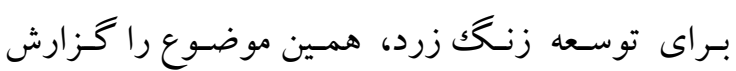
كردماند. هدف از اين تحقيق ارزيابى حساسيت ارقـام گنـدم

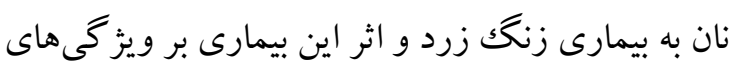
زراعى و فيزيولوزيكك ارقام كندم نان بود.

\section{مواد و روشها}

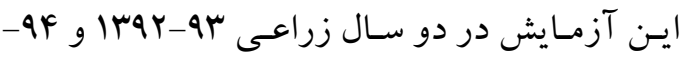

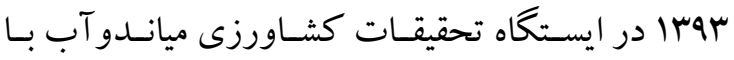

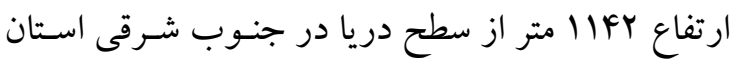

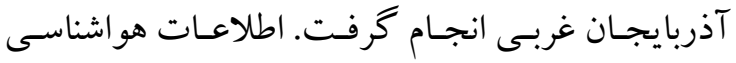
محل اجراى آزمايش در جدول الدرائه شده است.

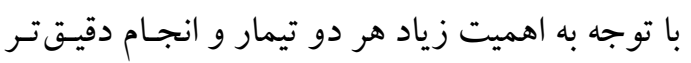

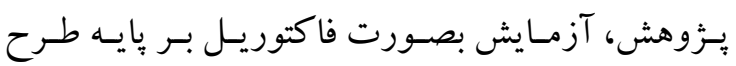

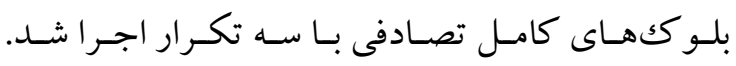

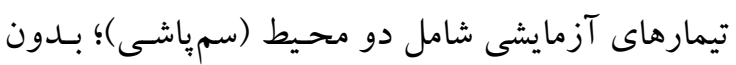

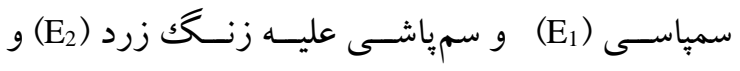

\section{مقدمه}

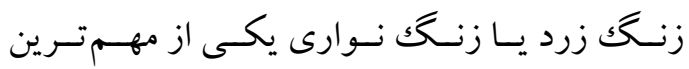
بيماريهاى گندم در اغلب مناطق دنيا محسوب مسى شئسود.

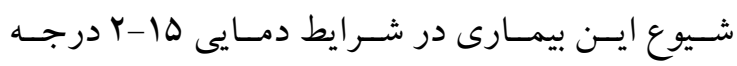

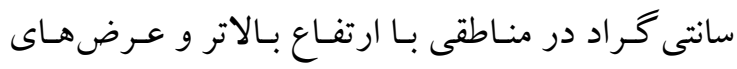

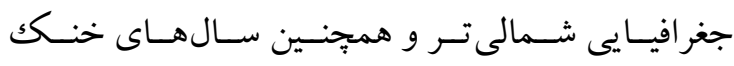

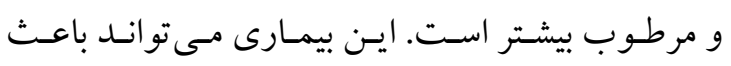

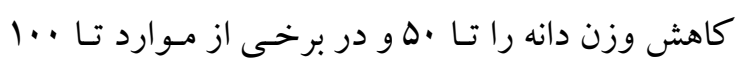
درصـد شـود (Singh et al., 2005). ترابس و همكـاران كز ارش نمودنــ كـه در ايـران (Torabi et al., 1995)

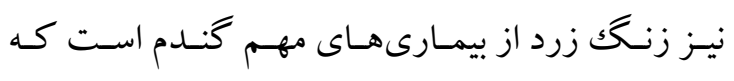

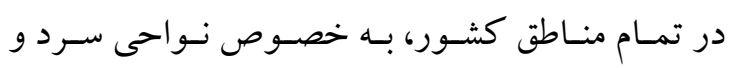

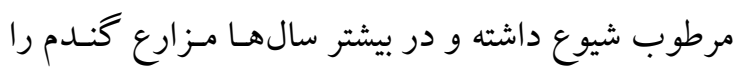

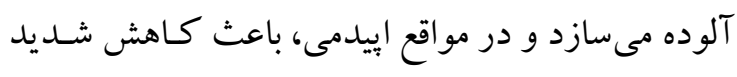

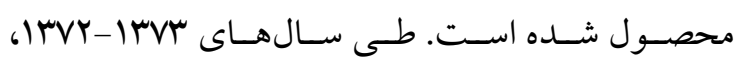

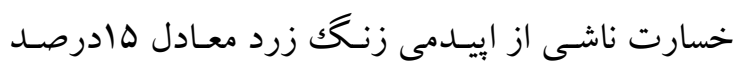

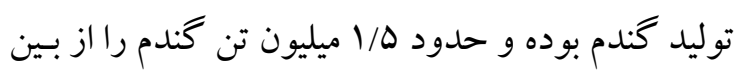

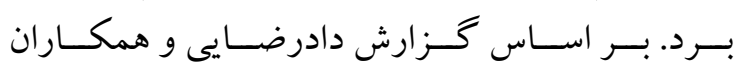
تحمل ارقام منتخب كنـدم بــ (Dadrezaei et al., 2018) بيمـارى زنــك زرد متفـاوت بـوده و خسـارت كـاهش

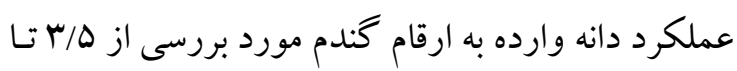
هV

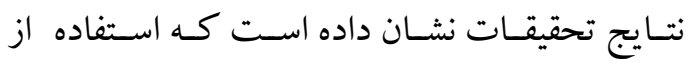

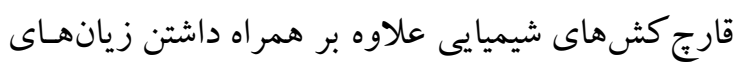

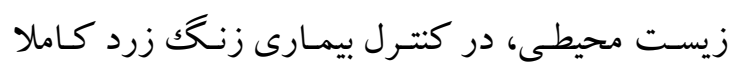

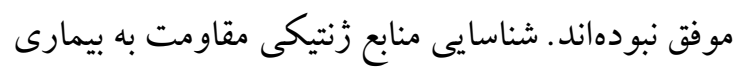

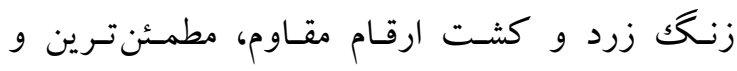
اصولى ترين روش كنترل اين بيمارى و كاهش خسارت

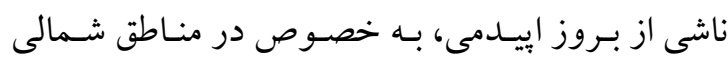
كشور اسـت (Nazari et al., 2000; Saidi et al., 2001). براساس نتايج بازديدهاى مزرعهاى در مناطق سردسيرى

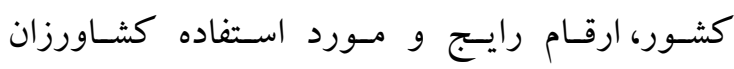

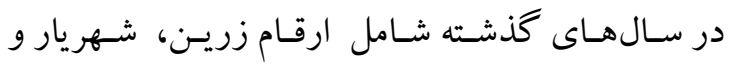

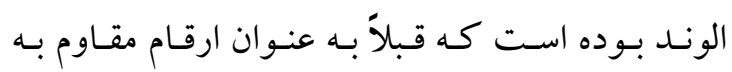




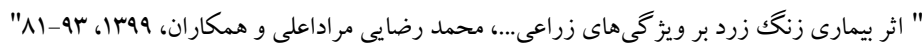

جدول ا- اطلاعات هواشناسى محل اجراى آزمايش (سو-rqrا و qF-rqr|)

Table1. Meteorological information in the experiment site (2013-2014 and 2014-2015)

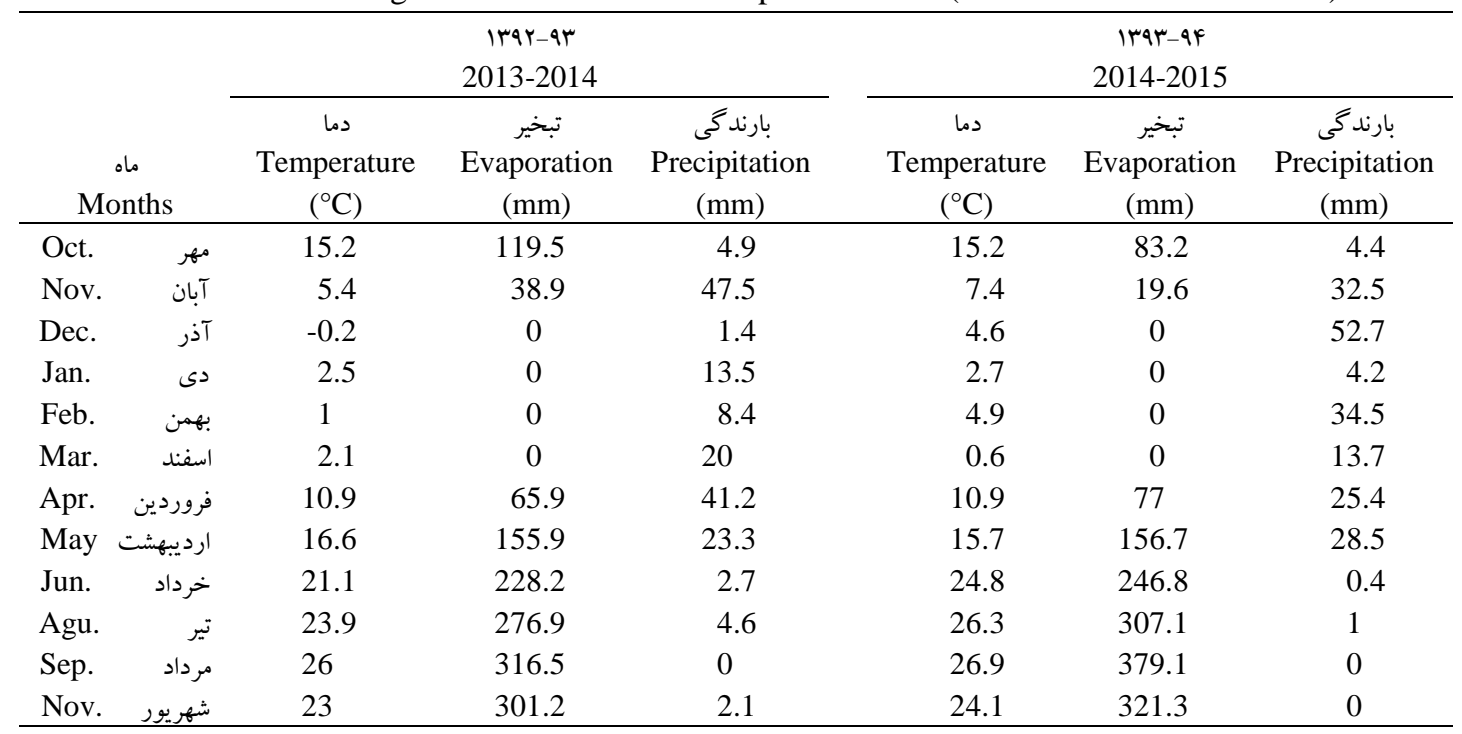

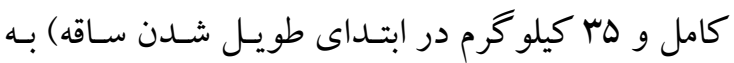

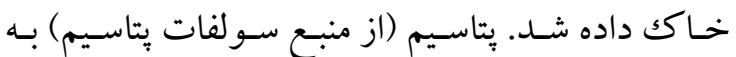

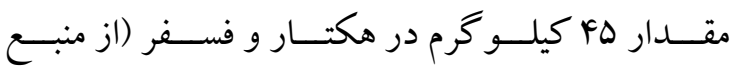

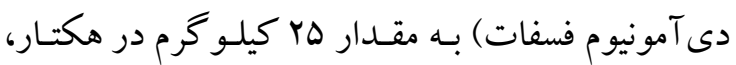
همزمان با كاشت به خاكك داده شدند. كاشت با استفاده

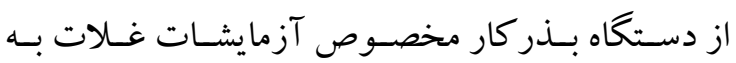
صورت خطى انجام شد. طول كرتهاى آزمايشى جهار

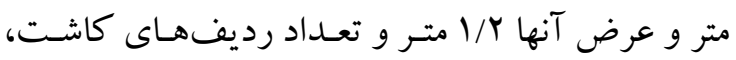
شش رديـف بـود. كاشـت بـذر در ·r مهر انجـام شـد.

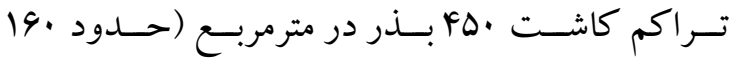

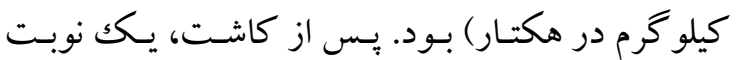

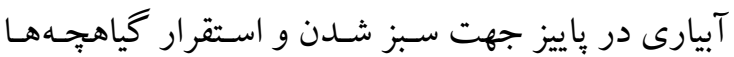

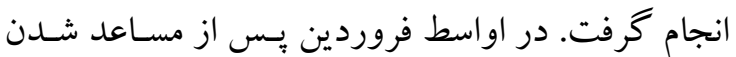

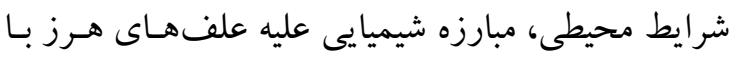

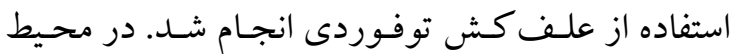

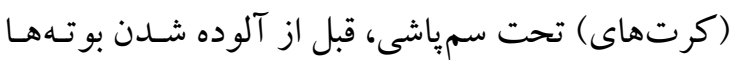

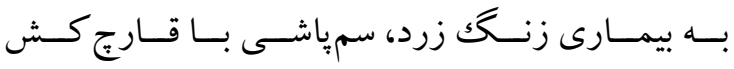
بروييكونـازول (تيلـت؛ EC25\%) بـهـ مقــدار نسيم ليتـر در

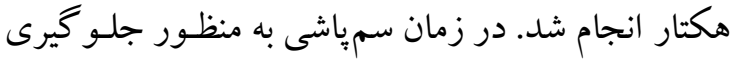

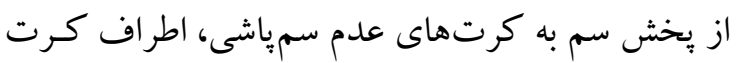

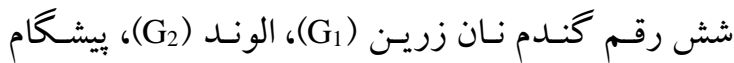
ز ز

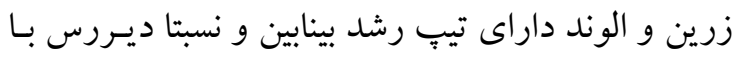

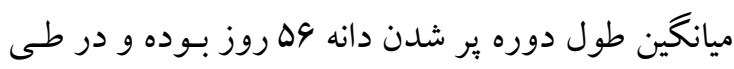

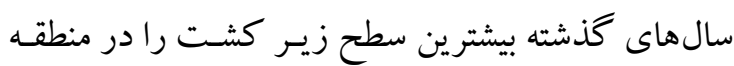

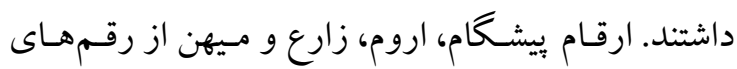
معرفى شده جديد موسسه تحقيقات اصلاح و تهيه نهال

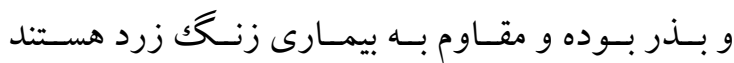
(Mahfoozi et al., 2009; Yazdansepas et al., 2017a; Yazdansepas et al., 2017b and Yazdansepas et al, 2017c)

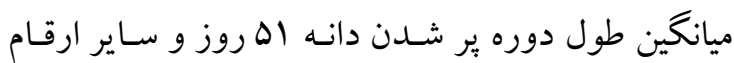

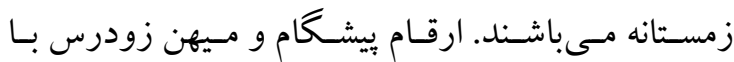

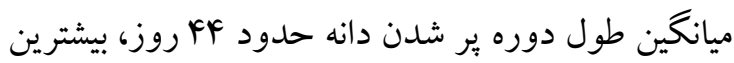

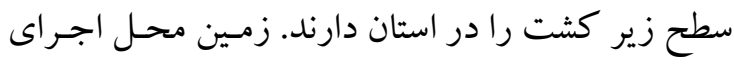
آزمايش ابتدا آبيارى و در اوايل مهر شخم زده شـد. بـر

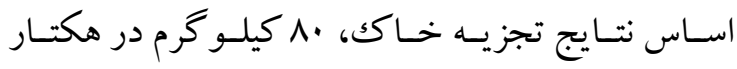

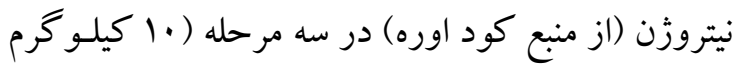

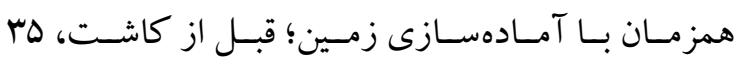

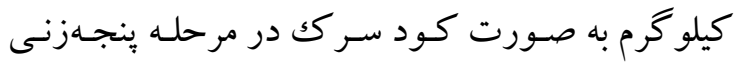


حساس (MS)= =1/· و حساس (S) =ا مشخص شد.

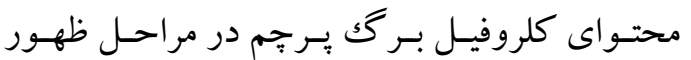

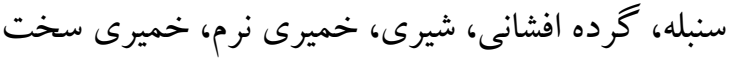

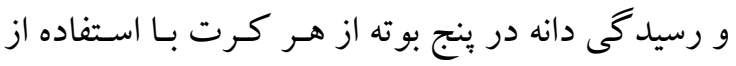
دستخاه كلروفيلمتر (SPAD502 Plus, Minolta, Japan)

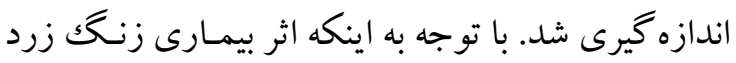

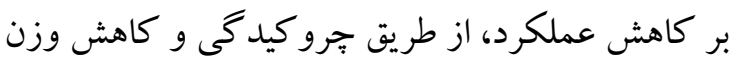

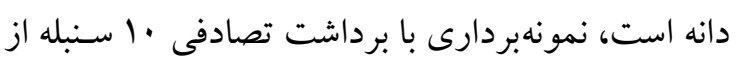

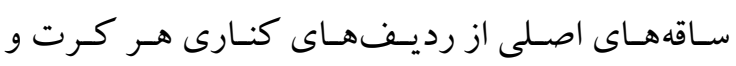

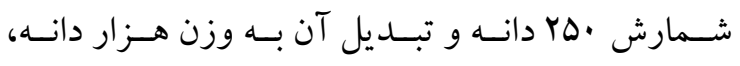

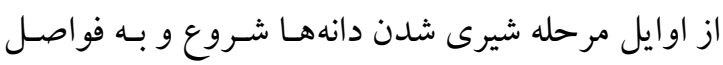
ينج روز تا رسيدگى كامل انجـام و نمـودار تغييـرات آن رسم شد. براى تعيين انتقال مجدد ماده خشكـك بـه دانـه در دو

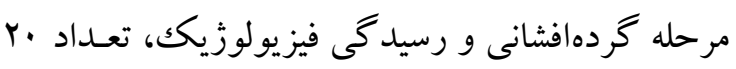

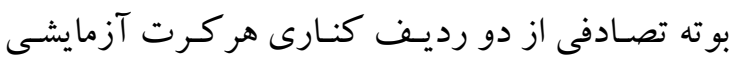
كفبر شده و سبس كل بو تههاى برداشت شـده در آون

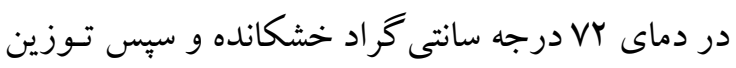

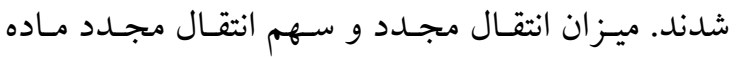

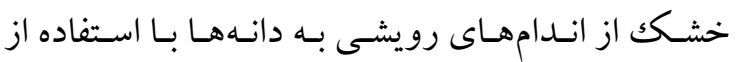
روشهـاى كـاكس و همكاران (Cox et al., 1990) و بإِاكوستا و گيانـاس (Papakosta and Gayians, 1991) محاسبه شدند (رابطههاى او ب):
با بلاستيك به ارتفاع دو متر محافظت شد. سمياشى در

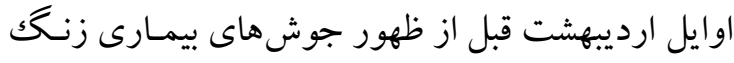
زرد در مرحله شروع طويل شدن ساقه و سه هفته بِ از از

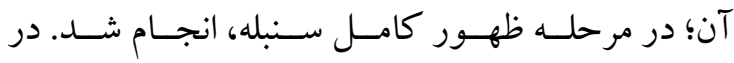
كرتهاى بدون سمياشى، بـــليل رطوبـت زيـاد محـل

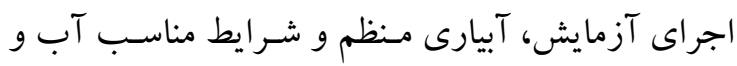

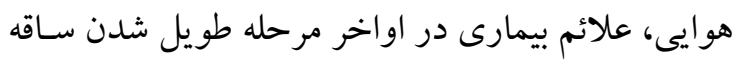
ظاهر و بتدريج توسعه يافت. ارزيابى ارقـام كنـدم مـورد

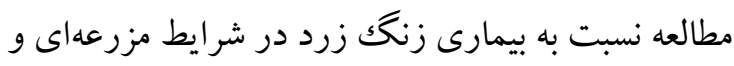

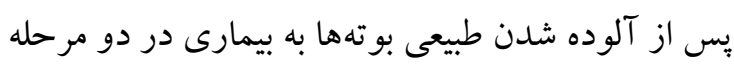

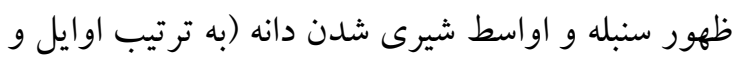
اواسط خرداد) انجام شد.

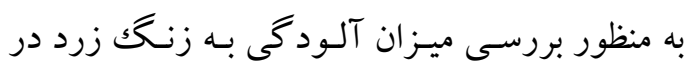

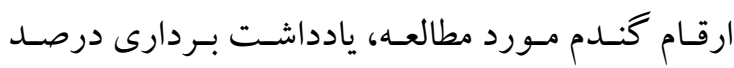

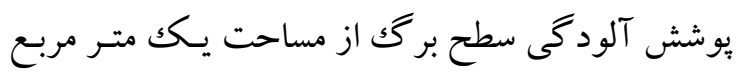

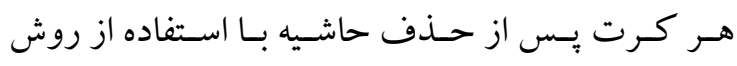

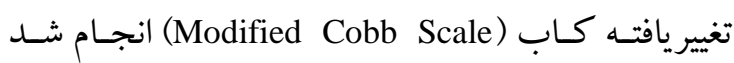
(Peterson et al., 1984)

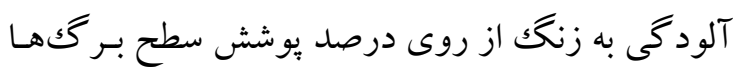

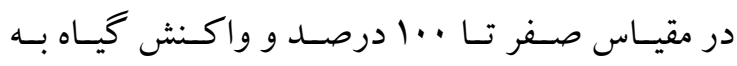

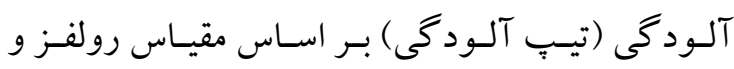

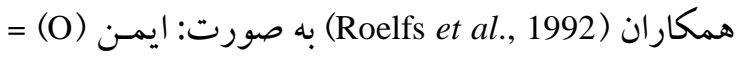

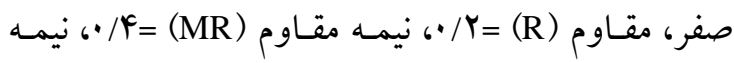

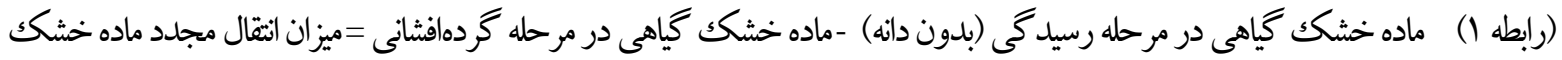

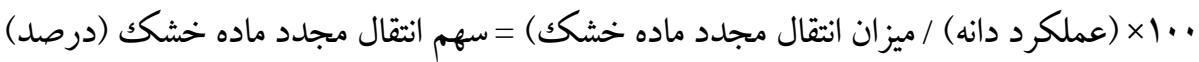

عملكرد زيست توده كياه برحسب درصد بدست آمـد.

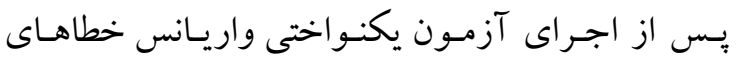

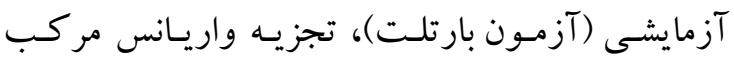

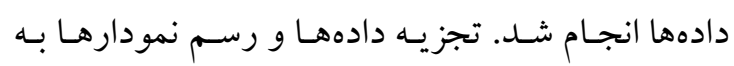
ترتيب با استفاده از نرمافزارهاى SPSS و ت

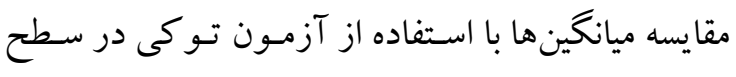
احتمال بِنج درصد انجام شد.
براى اندازه گيرى زيست تـوده، كليه بوتـهــاى هـر

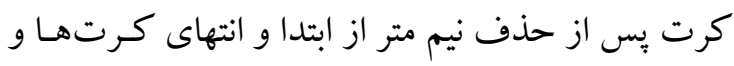

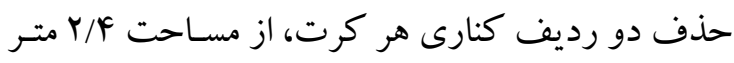

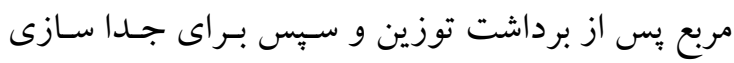
دانههـا از كمبـاين آزمايشـات غـلات (وينتـر اشـتايخر) استفاده و عملكرد دانه به كيلو گرم در هكتار تبديل شد. شاخص برداشت از تقسيم عملكـرد اقتصـادى (دانـه) بـر 


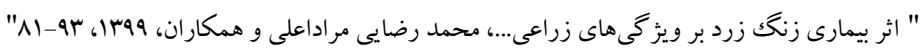

دى اكسيد كربن، بـه دليـل كـاهش سـطح سـبز فتوسـنتز كننده گيـاه در ارقـام حسـاس كنـدم شـده و اسـتفاده از ارقام مقاوم در برنامههاى بهنزادى بـراى كنتـرل بيمـارى

مى تواند مفيد باشد ( Abdulbagiyeva et al., 2015). تغييرات محتواى كلروفيل بـرك نشـان داد كـه در ارقام حسـاس زريـن و الونـد، در تيمـار بــدون سمياشى كاهش ميزان كلروفيل از مرحله كَلـدهى شـروع شـده و در مرحله شيرى شدن تا خميرى سخت، روند كاهش بـا شيب بيشترى ادامه يافت و در هر دوسـال آزمـايش ايسن نتيجـه مشـاهده شـد، ولى در تيمـار سمياشـى، تغييـرات محتواى كلروفيل برك در مراحل مختلف رشد دانـه تـا

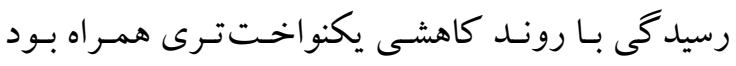
(شـكلهـاى او Y). در هـر دو سـال آزمـايش محتـواى كلروفيل بركَ از مرحله كلدهى تـا رسـيدگى كامـل در تيمار سمياشى بيشتر از تيمار بــدون سمياشسى بـود، ولى در ارقام مقاوم، محتواى كلروفيل بر گك و روند تغييـرات آن در تمام مراحل رشـد دانـه در هـر دو سـال آزمـايش

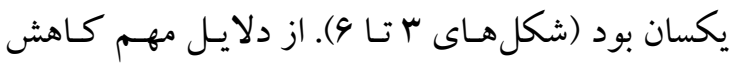

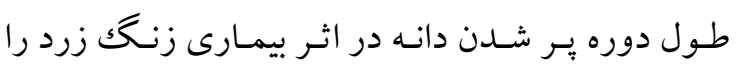
مى توان بـه كـاهش سـطح سـبز كيـاه، كـاهش محتـواى كلروفيل بركَ و كاهش دوام سطح بـر گك اشـاره نمـود. كـارترو و همكــاران(Carretero et al., 2011) اظهـار داشتند كه كاهش توان فتوسنتزى بر گها در اثر بيمارى زنگگ زرد در گُندم بدليل كاهش محتـواى كلروفيـل در قسمت هاى سبز رنگك بر گكهاى بيمـار اسـت، بطوريكه. ميزان كلروفيل (عدد كلروفيلمتر) در بـركَهـاى بيمـار

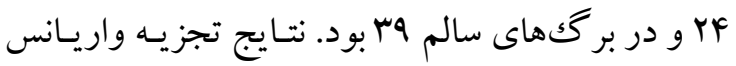
نشان داد كه اثـر محـيط (سمياشى)، رقمم و بـرهمكنش محيط در رقـم بـر وزن هـز ار دانـه معنسىدار بـود. نتـايج مقايسه ميانگين ها نشان داد كه در تيمار بـدون سمياشى

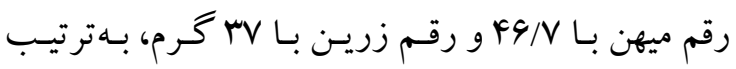
بيشـترين و كمتـرين مقــاروزن هـزار دانـه را داشـتند و

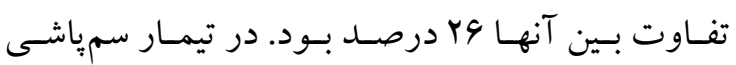

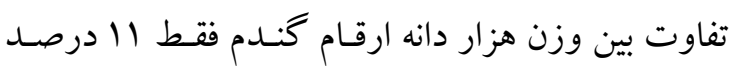

\section{نتايج 9 بحث}

با توجه به شرايط آب و هوايى خنك ارديبهشت در هر دوسال آزمايش و رطوبت كافى هوا، استقرار طبيعى زنـگك زرد بطـور طبيعسى روى ارقـام حسـاس صـورت

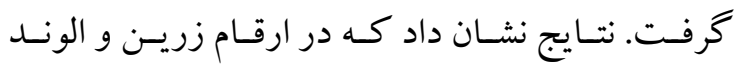
ميـانگين آلـود كى بـه بيمـارى زنسك زرد در دو سـال

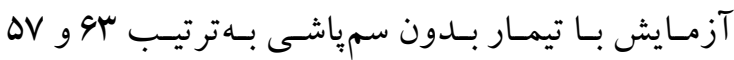
درصد بود، در صورتى كه در تيمار با سمياشى، بيمـارى

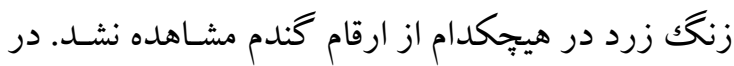
تيمار بدون سمياشى ارقـام بيشــام، اروم، زارع و مسيهن

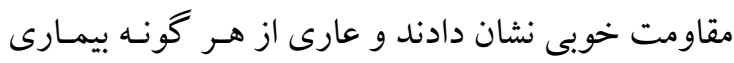
زنگك زرد بودند، بنابراين با توجه به ايسن نتـايج اثر ايسن بيمارى بر صـفات زراعسى و فيزيولوزيـك ارقـام گنـدم مورد بررسى قرار گرفت.

نتايج تجزيه واريانس نشان داد كه اثر سـال، محسيط (سمياشى) و برهمكنش محيط در رقم بر طـول دوره يـر

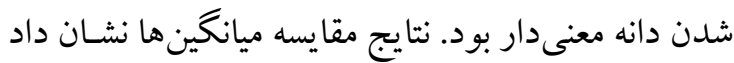
كه سال اول نسبت به سال دوم با سم روز، دوره بر شدن دانـه طـولانى تـرى داشـت (جـــول Y). از دلايـل ايسن موضوع مى توان به ميانكين دمـا و تبخيـر تجمعى بيشـتر ماههاى خرداد و تير در سال دوم اشاره كرد كـه باعث كاهش طول دوره ير شدن دانه شد. مقايسـه ميـانگينهـا نشـان داد كـه در ميـانكين دو سـال آزمـايش، در تيمـار سمياشى بيشترين طول دوره ير شدن دانه مربوط به رقـم الوند (Fq روز) بوده و در تيمـار بــدون سمياشس، طـول دوره ير شدن دانه به F ب روز در رقم زرين كـاهش بيـدا كرد (جدول ץ). تفـاوت بـين طـول دوره يـر شـدن دانـه ارقام زرين و الوند در دو تيمار بهترتيب 9 و ال روز بود و زنگك زرد باعث كاهش طول دوره يـر شـدن دانـه، بــ دليل كـاهش محتـواى كلروفيـل بـركَ و كـاهش تـوان فتوسنتزى كياه شد، در حاليكه در ارقام مقاوم بيشـام و مسيهن طـول دوره يسر شــدن دانسه در دو تيمـار تفــاوت

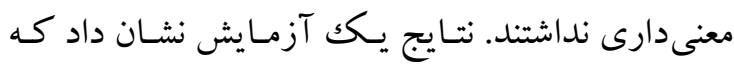
زنگك زرد بطور جـدى باعـث كـاهش فتوسـنتز و تثيـت 


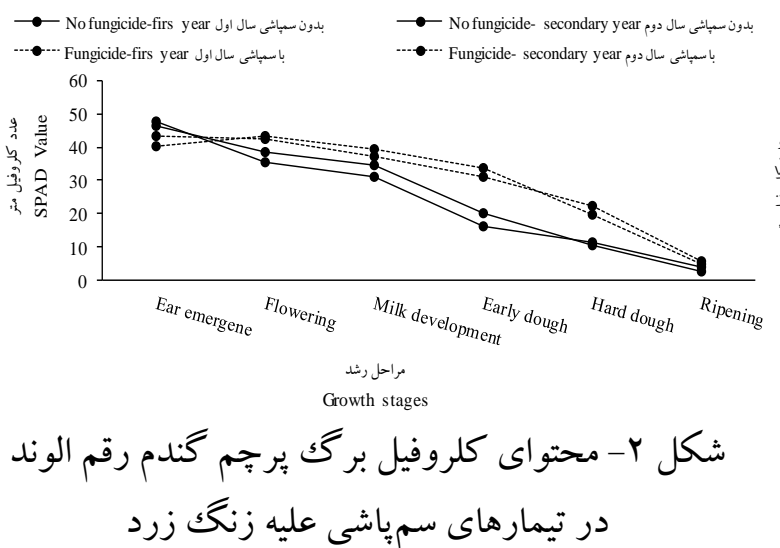

Fig. 2. Flag leaf chlorophyll content of wheat

cv. Alvand in fungicide application treatments

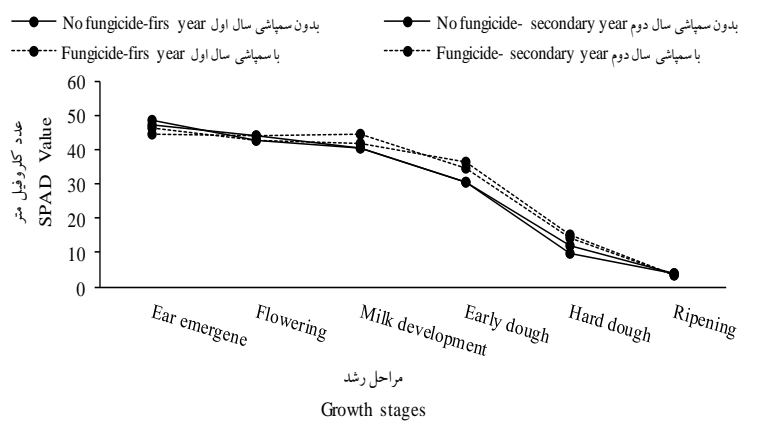

$$
\text { شكل F- محتواى كلروفيل برگك ير ¥جم گندم رقم اروم }
$$$$
\text { در تيمارهاى سمياشى عليه زنگك زرد }
$$

Fig. 4. Flag leaf chlorophyll content of wheat

cv. Oroum in fungicide application treatments

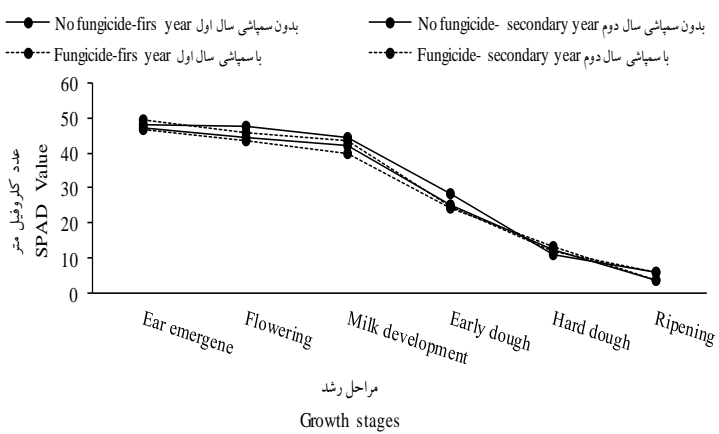

$$
\begin{aligned}
& \text { شكل 9- محتواى كلروفيل بر گك برجم كُندم رقم ميهن } \\
& \text { در تيمارهاى سمياشى عليه زنگك زرد }
\end{aligned}
$$

Fig. 6. Flag leaf chlorophyll content of wheat cv. Mihan in fungicide application treatments

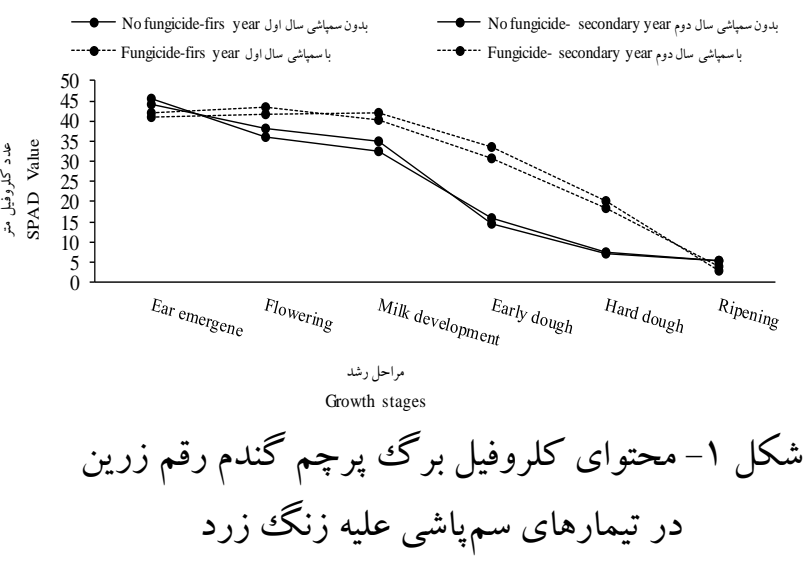

Fig. 1. Flag leaf chlorophyll content of wheat cv. Zarrin in fungicide application treatments

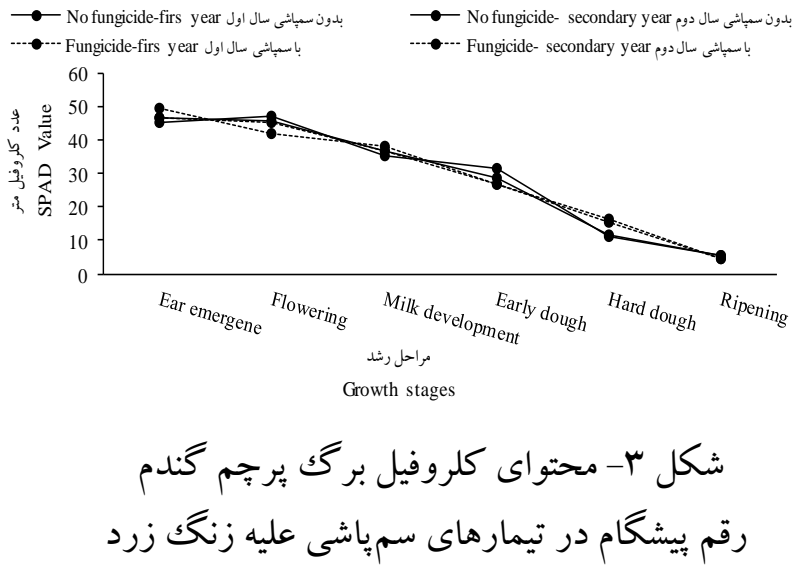

Fig. 3. Flag leaf chlorophyll content of wheat

cv. Pishgam in fungicide application treatments

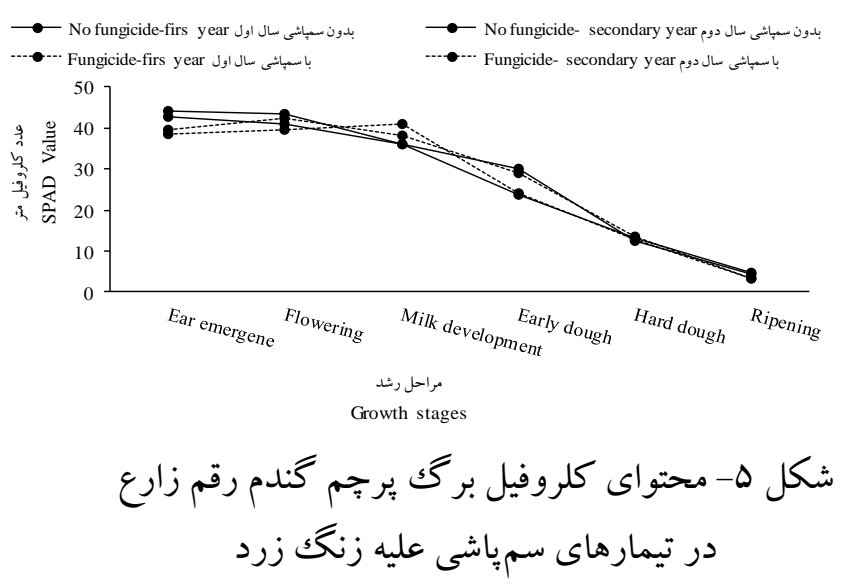

Fig. 5. Flag leaf chlorophyll content of wheat cv. Zareh in fungicide application treatments 


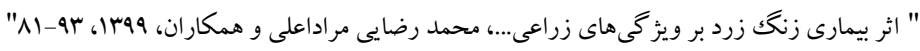

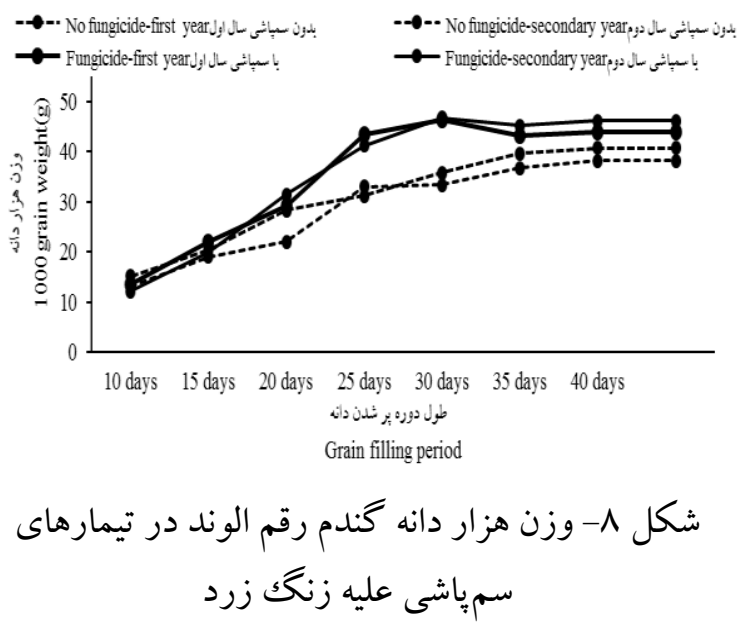

Fig. 8. 1000 grain weight of wheat cv. Alvand in fungicide application treatments

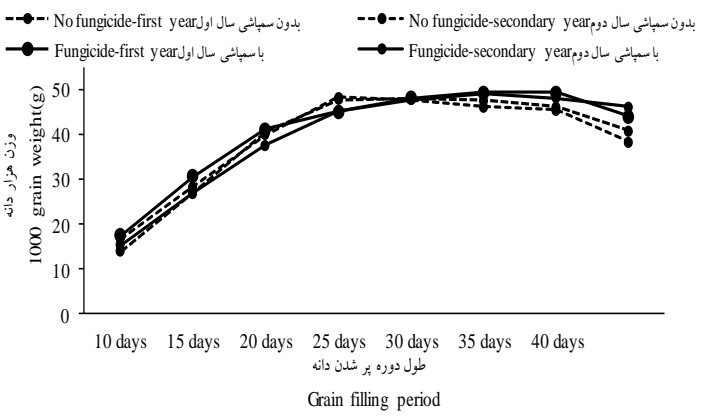

$$
\begin{aligned}
& \text { شكل · 1- وزن هزار دانه گُندم رقم اروم در تيمارهاى } \\
& \text { سمبياشى عليه زنخك زرد }
\end{aligned}
$$

Fig. 10.1000 grain weight of wheat cv. Oroum in fungicide application treatments

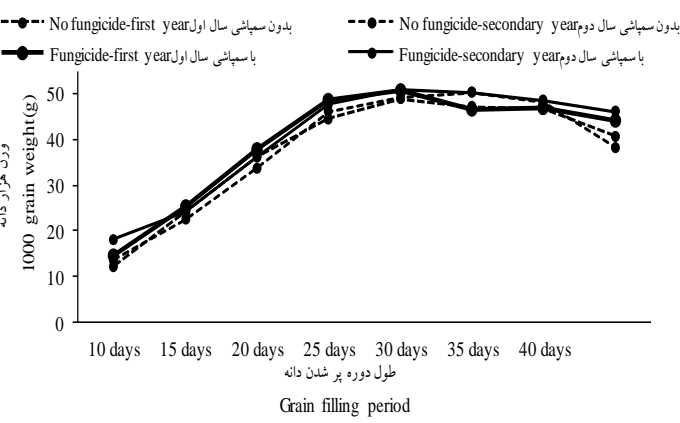

شكل rا - وزن هزار دانه كندم رقم ميهن در تيمارهاى

$$
\text { سمياشى عليه زنگك زرد }
$$

Fig. 12. 1000 grain weight of wheat cv. Mihan in fungicide application treatments

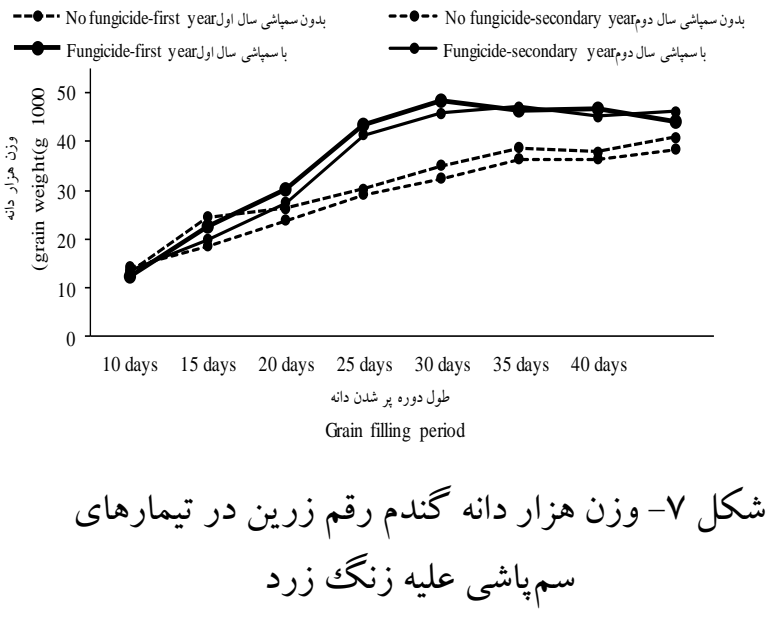

Fig. 7. 1000 grain weight of wheat cv. Zarrin in fungicide application treatments

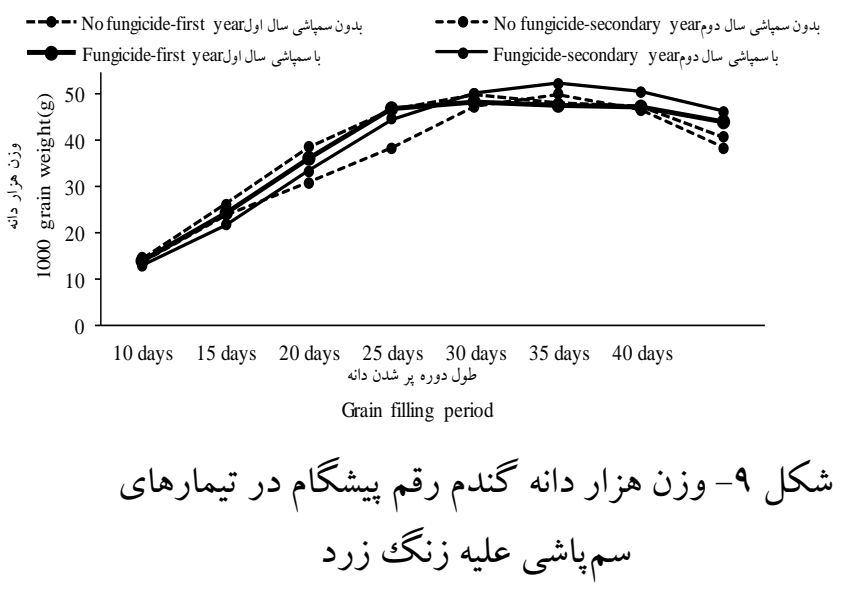

Fig. 9. 1000 grain weight of wheat cv. Pishgam in fungicide application treatments

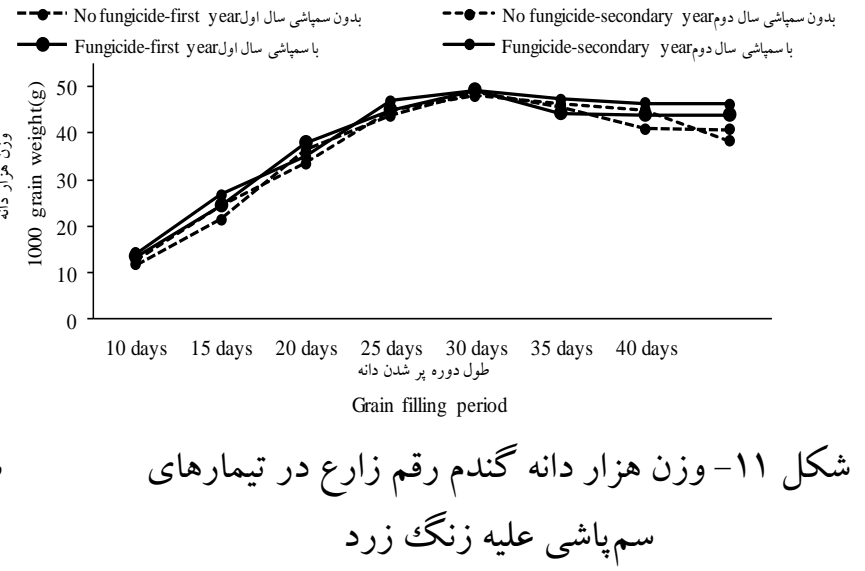

Fig. 11. 1000 grain weight of wheat cv. Zareh in fungicide application treatments 


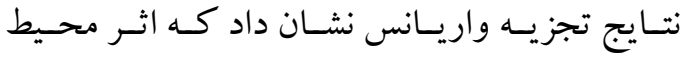

(سمياشى)، رقم و بـرهمكنش محـيط در رقـم بـر سـهم انتقال مجدد معنى دار بود. در تيمـار بـدون سمياسـى، بـا استقرار زنكگ زرد در ارقـام حسـاس و كـاهش فتوسـنتز كياه، سـهم انتقـال مجـدد در پير كـردن دانسه بيشـتر بـود. نتايج نشان داد كه هر دو رقم كندم زرين و الونـد سـهم انتقال مجدد بيشترى نسبت به ساير ارقام داشتند (جـدول r). بـرهمكنش محسيط در رقـم نشـان داد كـه در تيمـار

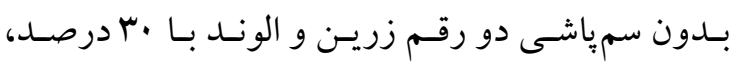
بيشترين سهم انتقال مجــد را داشـتند، ولى در تيمـار بـا سميّاشى تفاوت معنى دارى بين ارقام وجـود نداشـت. بـا

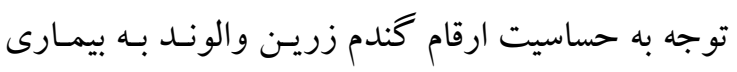

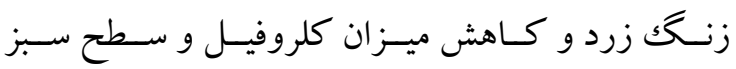
اين ارقام در شر ايط بروز بيمارى، وابستخى دانه بـه مـواد ذخيرهاى قبل از كلـدهى و انتقـال مجــد آنهـا در ارقـام حساس نسـبت بـه ارقـام مقــاوم بيشـتر بـود. بطور كلـى تــنش هـاى محيطـى (زيسـتى و غيــر زيسـتى ) باعـث

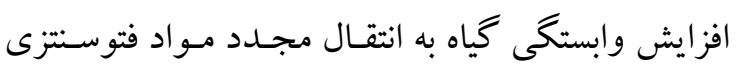

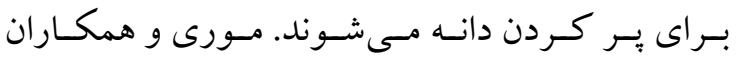

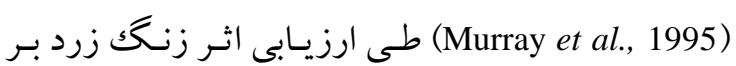

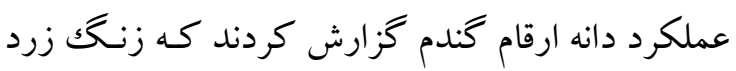

بـود و نشـان دهنــده ايسن اسـت كـه در شـرايط كنتـرل بيمارى، وزن دانه ارقام حساس نظير الوند و زرين بيشـتر شده و تفاوت معنى دارى از نظر وزن هزار دانه بين ارقـام حسـاس و مقــاوم وجـود نداشـت (جـدول م). تفــاوت وزن هزار دانه ارقام حساس زريسن و الونسـ در دو تيمـار سمياشى و بدون سمياشى بهترتيب و Y و Fl در صسورتيكه در ارقـام مقــاوم تفـاوت معنسىدارى در

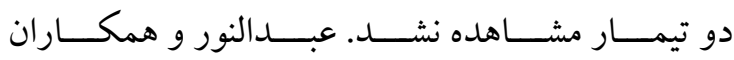
(Abdennour et al., 2018) عملكرد و اجزاى عملكـرد دانـه ارقـام بهـاره كنـدم نـان اعلام كردند كه زنگك زرد باعث كـاهش اس درصـد در وزن هزار دانه ارقام حساس در شـرايط بـدون سمياشـى شد. در هر دو سال آزمـايش در ارقـام حسـاس زريسن و وركام الوند در تيمار بدون سمياشى، رونــ كـاهش وزن هـزار دانه در ها روز يّ از شروع ير شدن دانه مشاهده شـده و وزن هزار دانه تا يايان دوره رسيدكى نسـبت بـه تيمـار سمياشـى كمتــ بـود. در صسورتيكه در تيمـار سمياشىى روند رشد دانه و افزايش وزن آن تا يايان رسيدگى ادامه به داشته و سبيس تقريبا ثابت ماند. روند رشد دانه و افزايش وزن آن در ارقام مقاوم در هر دو تيمار يكنواخـت بـوده و بيمارى زنگك زرد بـر رشـد و افـزايش وزن دانسه آنهـا

تاثيرى نداشت (شكل هاى V تا Y I).

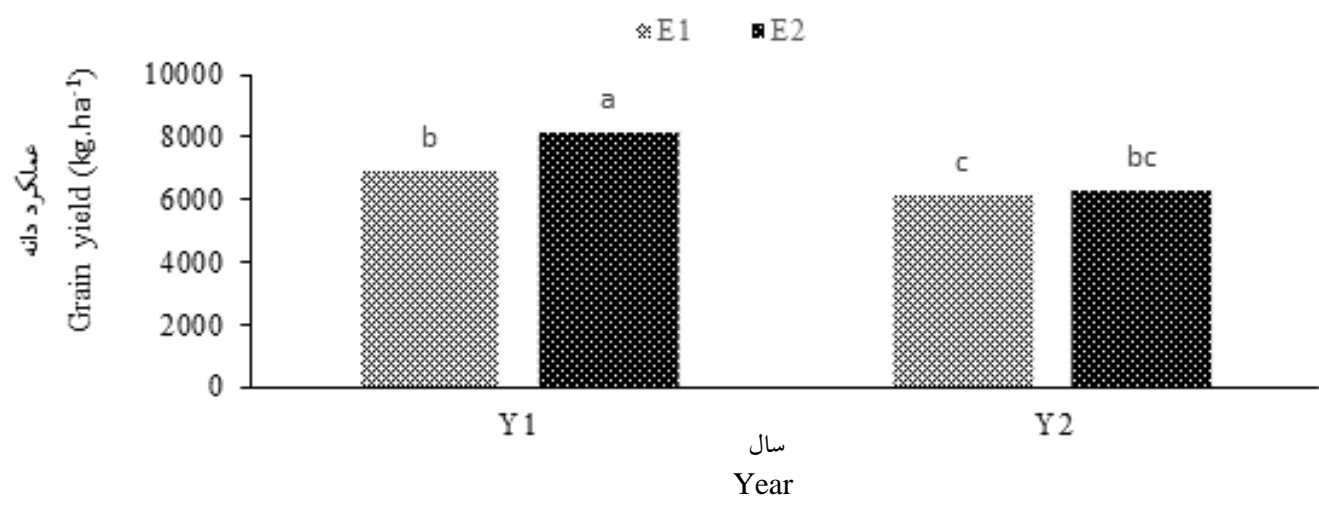

شكل ما - برهمكنش سال در محيط (سمياشى عليه بيمارى زنخك زرد) بر عملكرد دانه ارقام گندم

Fig. 13. Interaction effect of year $\times$ environment (fungicide application) on grain yield of wheat cultivars

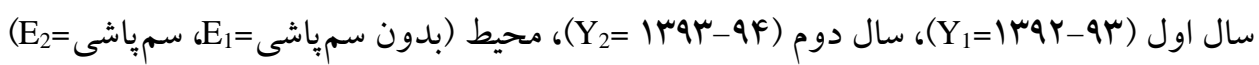

First year; $Y_{1}(2013-2014)$, Second year; $Y_{2}$ (2014-2015), Environment ( $E_{1=}$ No fungicide, $E_{2}=$ Fungicide) 


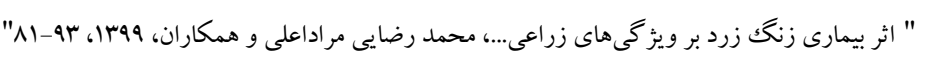

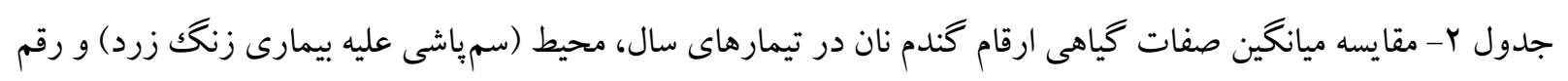

Table 2. Mean comparison of plant characteristics of bread wheat cultivars in year, fungicide application against yellow rust disease and cultivar treatments

\begin{tabular}{|c|c|c|c|c|c|c|}
\hline Treatments & ت تيمارهاي آزمايشى & $\begin{array}{c}\text { دوره يرشدن دانه (day) } \\
\text { Grain filling period (d) }\end{array}$ & $\begin{array}{c}\text { وزن هزار دانه } 1000 \text { grain weight (g) } \\
100 \text { (a) }\end{array}$ & $\begin{array}{c}\text { سهم انتقال مجدد (\%) } \\
\text { Remobilization contribution (\%) }\end{array}$ & $\begin{array}{c}\text { عملكرد دانه } \\
\left.\text { Grain yield (kg.ha- }{ }^{1}\right)\end{array}$ & $\begin{array}{c}\text { شاخص برداشت } \\
\text { Harvest index (\%) }\end{array}$ \\
\hline 2013-2014 & irar-ar & $43 \mathrm{a}$ & $45.3 \mathrm{a}$ & $26.3 \mathrm{a}$ & $7593 a$ & $49.9 \mathrm{a}$ \\
\hline 2014-2015 & IrqT_qf & $40 b$ & $44.5 \mathrm{a}$ & $25.2 \mathrm{a}$ & $6261 b$ & $47.8 \mathrm{~b}$ \\
\hline No fungicide & بدون سمياشى سمياشى ل & $40 \mathrm{~b}$ & $43.0 \mathrm{~b}$ & $27.3 \mathrm{a}$ & $6574 b$ & $48.2 \mathrm{a}$ \\
\hline Fungicide & 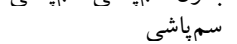 & $43 a$ & $46.8 \mathrm{a}$ & $24.2 b$ & $7280 a$ & $49.5 \mathrm{a}$ \\
\hline Wheat cultivars & ارقام كَندم & & & & & \\
\hline Zarrin & زرين & $41 \mathrm{a}$ & $41.8 \mathrm{~b}$ & $29.6 \mathrm{a}$ & $5974 b$ & $47.0 \mathrm{~b}$ \\
\hline Alvand & الوند & $41 \mathrm{a}$ & $42.3 b$ & $29.5 a$ & $5972 b$ & $45.8 \mathrm{~b}$ \\
\hline Pishgam & ييشكام & $41 \mathrm{a}$ & $47.5 \mathrm{a}$ & $24.4 \mathrm{~b}$ & $7877 \mathrm{a}$ & $52.8 \mathrm{a}$ \\
\hline Oroum & ارتوم & $43 a$ & $46.8 \mathrm{a}$ & $21.9 b$ & $6921 \mathrm{ab}$ & $49.3 \mathrm{ab}$ \\
\hline Zareh & 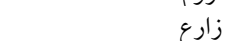 & $43 a$ & $43.9 \mathrm{~b}$ & $24.8 \mathrm{~b}$ & $7224 a$ & $49.4 \mathrm{ab}$ \\
\hline Mihan & ميهن & $40 \mathrm{a}$ & $47.1 \mathrm{a}$ & $24.4 \mathrm{~b}$ & $7593 a$ & $48.8 \mathrm{ab}$ \\
\hline
\end{tabular}

Means in each column followed by similar letter(s) are not significant different at 5\% probability level, using Tukey's Test

$$
\text { جدول س- مقايسه ميانگين صفات گياهى ارقام گندم نان در برهمكنش تيمارهاى محيط (سمياشى عليه بيمارى زنگك زرد) و رقم }
$$

\begin{tabular}{|c|c|c|c|c|c|c|}
\hline \multirow{3}{*}{$\begin{array}{c}\text { تيمارهاى آزمايشى } \\
\text { Treatments } \\
\text { بدون سمياشى } \\
\text { No fungicide }\end{array}$} & \multicolumn{2}{|c|}{$\begin{array}{c}\text { ارقام گُندم } \\
\text { Wheat cultivars }\end{array}$} & \multirow{2}{*}{$\begin{array}{c}\text { دوره يرشدن دانه (day) } \\
\text { Grain filling period (da) } \\
34.8 \mathrm{e}\end{array}$} & \multirow{2}{*}{$\begin{array}{c}1000 \text { grain weight (g) } \\
37.0 \mathrm{e}\end{array}$} & \multirow{2}{*}{$\frac{\begin{array}{c}\text { سهم انتقال مجداد } \\
\text { Remobilization contribution (\%) }\end{array}}{30.3 \mathrm{a}}$} & \multirow{2}{*}{$\begin{array}{c}\text { شاخص برداشت } \\
\text { Harvest index (\%) } \\
42.8 \mathrm{~b}\end{array}$} \\
\hline & Zarrin & زرين & & & & \\
\hline & Alvand & الوند & 38.0de & 39.5de & $30.7 \mathrm{a}$ & $43.0 \mathrm{~b}$ \\
\hline \multirow{10}{*}{ سمياشى } & Pishgham & يبشكام & $41.3 \mathrm{~b}-\mathrm{e}$ & $47.3 \mathrm{bc}$ & $22.8 b$ & $52.8 \mathrm{a}$ \\
\hline & Oroum & اروم & $44.7 \mathrm{abc}$ & $46.3 \mathrm{abc}$ & $22.2 b$ & $50.2 \mathrm{ab}$ \\
\hline & Zareh & زارع & $42.5 \mathrm{a}-\mathrm{d}$ & $43.2 \mathrm{~cd}$ & $23.3 b$ & $51.3 \mathrm{a}$ \\
\hline & Mihan & ميهن & $39.0 c-e$ & $46.7 \mathrm{abc}$ & $23.5 b$ & $48.8 \mathrm{ab}$ \\
\hline & Zarrin & زرين & $47.0 \mathrm{ab}$ & $46.5 \mathrm{abc}$ & $23.8 \mathrm{~b}$ & $48.2 \mathrm{ab}$ \\
\hline & Alvand & الوند & $48.7 \mathrm{a}$ & $45.0 \mathrm{bc}$ & $22.3 b$ & $47.5 \mathrm{ab}$ \\
\hline & Pishgham & بيشكام & $41.3 \mathrm{~b}-\mathrm{e}$ & $47.7 \mathrm{a}$ & $26.0 \mathrm{~b}$ & $52.8 \mathrm{a}$ \\
\hline & Oroum & اروم & $41.5 \mathrm{a}-\mathrm{d}$ & 47.3abc & $21.7 \mathrm{~b}$ & $48.3 \mathrm{ab}$ \\
\hline & Zareh & زارع & $43.7 \mathrm{a}-\mathrm{d}$ & $44.7 b c$ & $26.3 b$ & $47.5 \mathrm{ab}$ \\
\hline & Mihan & ميهن & $41.0 \mathrm{~b}-\mathrm{e}$ & $47.5 \mathrm{ab}$ & $25.3 \mathrm{~b}$ & $48.7 \mathrm{ab}$ \\
\hline
\end{tabular}

Table 3. Mean comparison of plant characteristics of bread wheat cultivars in interaction effect fungicide application against yellow rust disease and cultivar treatments

Means in each column followed by similar letter(s) are not significant different at 5\% probability level, using Tukey's Test 
كردند كه ميانگين درصـد كـاهش عملكـرد دانه ارقام

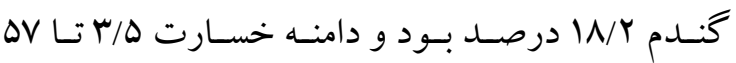

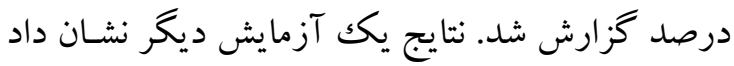

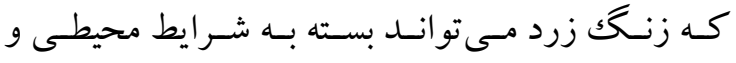

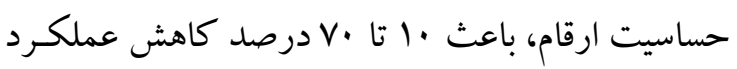
دانه گندم شود (Imtiaz et al., 2005). نتايج تجزيه واريانس نشان داد كه اثر سـال، رقـم و بـرهمكنش محسيط (سـمياشـى) در رقـم بـر شـاخص

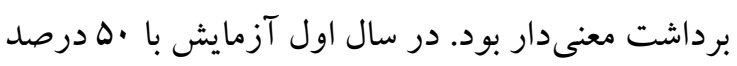

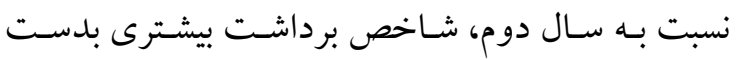

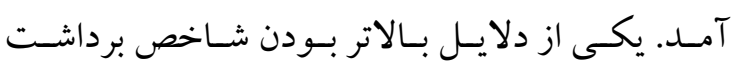

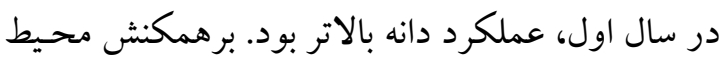

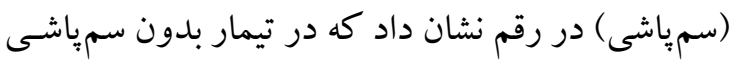
كمتـرين شـاخص برداشـت مربـوط بـهـ دو رقـم زريسن

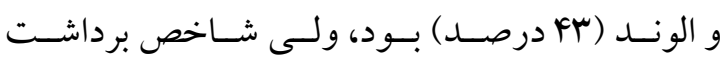

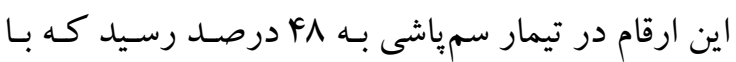
توجـه بـه افز ايش عملكـرد دانسه ايسن دو رقـم در تيمـار سمياشى، جنين نتيجهاى دور از انتظار نبود. نتايج مقايسه

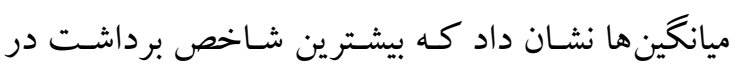

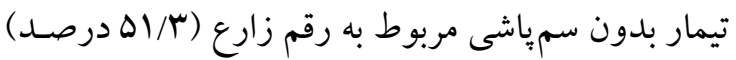

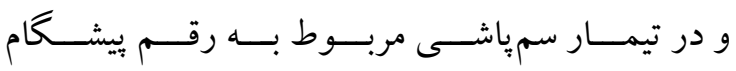

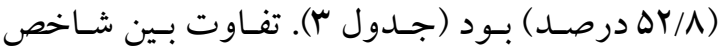

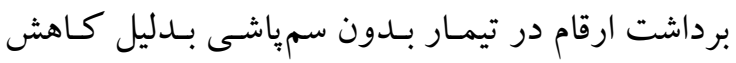

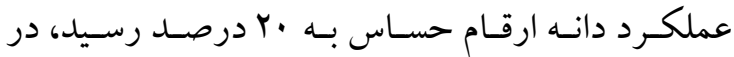

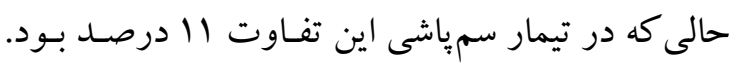

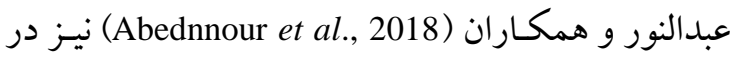

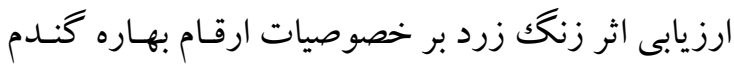

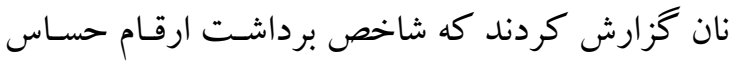

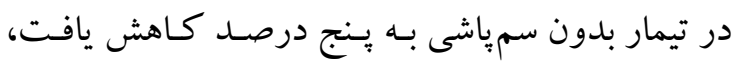

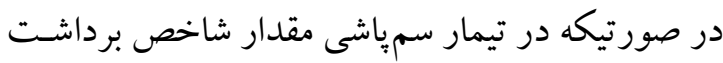
Y4 M درصد بود.

\section{نتيجه كيرى}

نتايج اين آزمايش نشان داد كـه اسـتقرار زنـگك زرد
تاثيرى بر وزن خشك ساقه (تا مرحله كَلدهى) نداشـت،

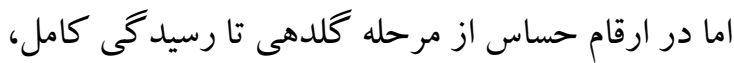
ماده خشك ساقه كاهش يافت كه دليل آنرا انتقال بيشتر مو اد فتوسنتزى ذخيرهاى ساقه به دانه و كـاهش فتوسـنتز

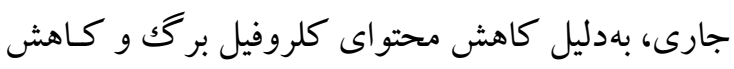
سطح فتوسنتز كننده گياه ذكر كردند.

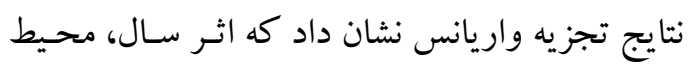
(سمباشى)، برهمكنش سال در محيط و رقم بر عملكرد

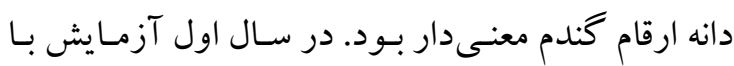

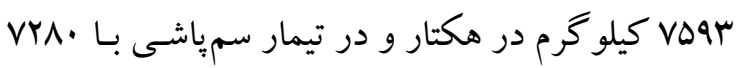

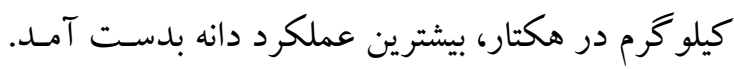
در برهمكنش سال در محيط نيز در هـر دو سـالآزمايش،

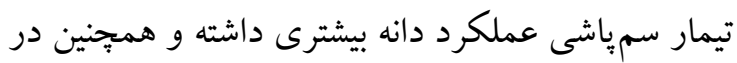

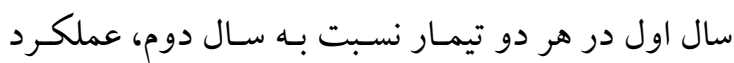
دانه بيشترى توليد شد. از دلايل بيشتر بودن عملكرد دانه

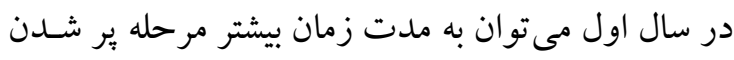

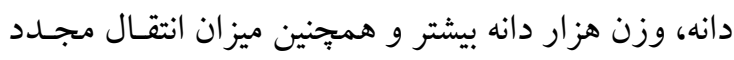

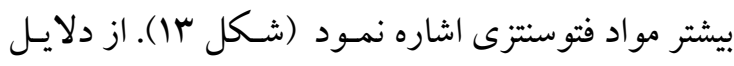

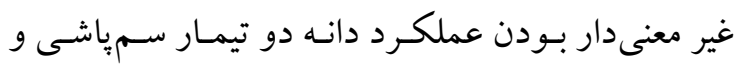

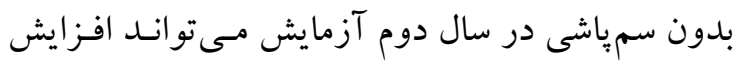

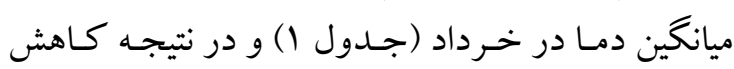
شدت كسترش بيمارى باشد.

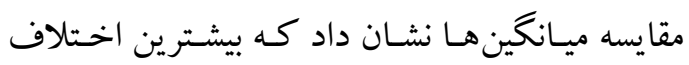

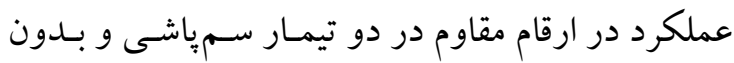

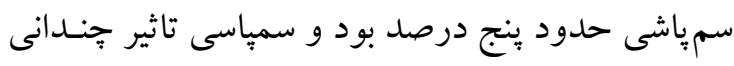

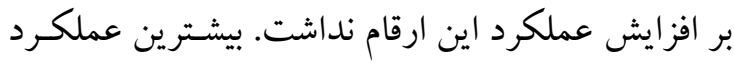

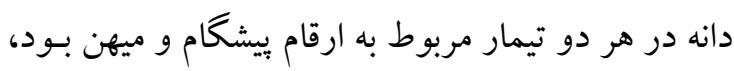

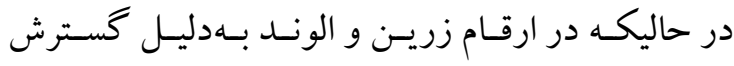

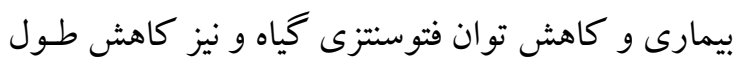

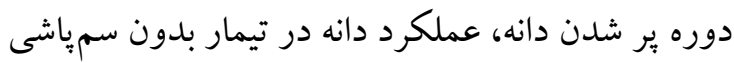

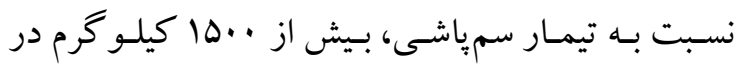

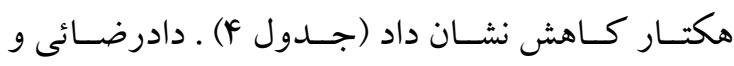

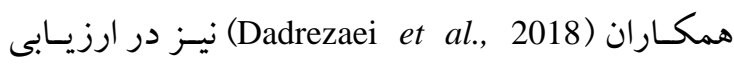
مقاومت ·r رقم كُندم نان بـه بيمـارى زنــك زرد اعـلام 


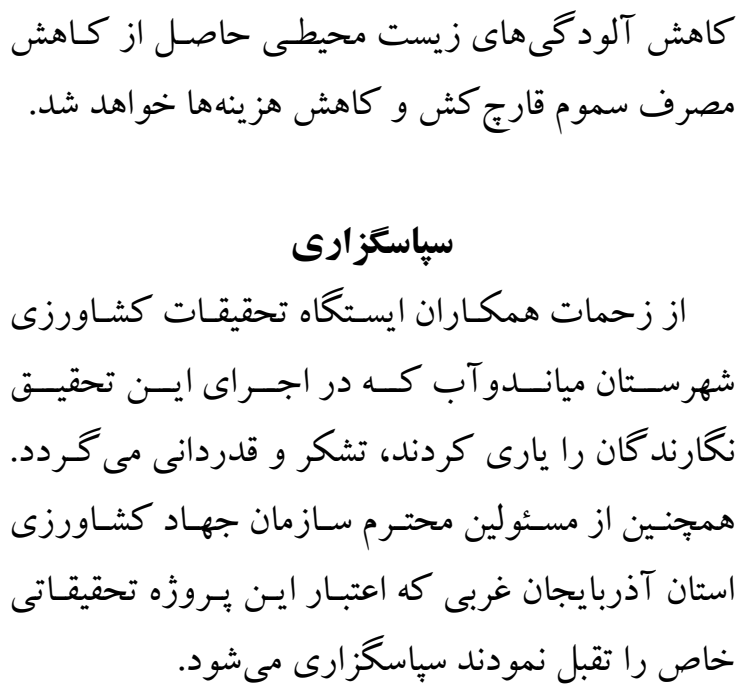

\section{References}

Abdennour, S., F. Sahbi1 and B. Houcine. 2018. Yellow rust effects on grain yield, and yield components of some spring bread wheat cultivars under rainfed conditions. World J. Agric. Res. 6(2): 65-69.

Abdulbagiyeva, S., A. Zamanov, J. Talai and T. Allahverdiyev. 2015. Effect of rust disease on photosynthetic rate of wheat plant. J. Agric. Sci. Technol. 5: 486-490.

Afshari, F. 2000. Studies on stripe rust resistance in wheat with particular emphasis on stripe rust. PhD Thesis, University of Sydney, Australia. 252 pp.

Afshari, F., K. Nazari and S. Ebrahimnejad. 2010. Identification of sources of resistance to stripe (yellow) rust in Iranian landraces of wheat. Proceedings of the $8^{\text {th }}$ International Wheat Conference, 30 May-4 June. St. Petersburg, Russia.

Agrios, G. N. 2004. Plant Pathology. (4 ${ }^{\text {th }}$ Ed.) Academic Press. New York, USA.

Cox, M. C., C. O. Qualset and D. W. Rains. 1990. Genetic variation for nitrogen assimilation and translocation in wheat. III: Nitrogen translocation in relation to grain yield and protein. Crop Sci. 26: 737-740.

Carretero, R., M. O. Bancal and D. J. Miralles. 2011. Effect of leaf rust (Puccinia triticina) on photosynthesis and related processes of leaves in wheat crops grown at two contrasting sites and with different nitrogen levels. Europ. J. Agron. 35 (4): 237-46.

Dadrezaei, S. R., A. Jafarnezhad, I. Lakzadeh, F. Afshari, Z. Hassan Bayat and N. Tabatabai. 2018. Evaluation of tolerance to yellow rust disease in some selected bread wheat cultivars. Seed Plant Improv. J. 32-1: 125-142. (In Persian with English abstract).

Imtiaz. M., M. G. Cromey, J. G. Hampton and F. C. Ogbonnaya. 2005. Genetics of stripe rust resistance in 'Karamu' wheat, Aust. J. Agric. Res. 56(6): 619-624.

Keshavarz, K. and M. Torabi. 1998. Resistance of recommended wheat cultivars to yellow rust in the Kohgilooye and Boyerahmad province (Iran). Proceedings of the $13^{\text {th }}$ Iranian Plant Protection Congress, 23- 


$$
\text { "نشريه علوم زراعى ايران"، جلد بيست و دوم، شماره ا، بهار }
$$

27 Aug., Karaj, Iran. (In Persian with English abstract).

Mahfoozi, S., A. Akbari, M. Chaichi, A. G. Sanjari, S. M. Nazeri, S. Abedi-Oskooee, G. Aminzadeh and M. Rezaie. 2009. Pishgam, a new bread wheat cultivar for normal irrigation and terminal stage deficit irrigation conditions of cold regions of Iran. Seed Plant Improv. J. 25(3): 513-517.

Murray, G. M., P. J. Ellison and A. Watson. 1995. Effects of stripe rust on the wheat plant. Aust. Plant Pathol. 24(4): 261-270.

Nazari, K., M. Torabi, M. Hasanpour, A. Kashani, R. Hooshyar and M. S. Ahmadian. 2000. Evaluation of resistance of rainfed cultivars and advanced lines of wheat to yellow rust in seedling and mature plant stage. Seed Plant. 16: (2): 252-263. (In Persian with English abstract).

Papakosta, D. K. and A. A. Gayians. 1991. Nitrogen and dry matter accumulation, remobilization and losses for Mediterranean wheat during grain filling. Agron. J. 83: 864-870.

Peterson, R. F, A. B. Campbell and A. E. Hannah. 1984. A diagrammatic scale for estimating rust intensity of leaves and stem of cereals. Can. J. Res. 26: 496-500.

Roelfs, A. P., R. P. Singh and E. F. Saari. 1992. Rust Diseases of Wheat: Concepts and Methods of Disease Management. Mexico, D.F.\CIMMYT, 81.

Saidi, A., M. Abedini Esfahani, G. Karimzadeh and A. Alizadeh. 2001. Inheritance of resistance to fusarium head blight in six wheat (Triticum aestivum L.) cultivars. Seed Plant. 17: 74-87. (In Persian with English abstract).

Singh, R. P., J. Huerta-Espinosa and H. M. William. 2005. Genetics and breeding for durable resistance to leaf and stripe rusts in wheat. Turk. J. Agric. Forest.29: 121-127.

Torabi, M., V. Mardokhi, K. Nazari, F. Afshari, A. R. Forootan, M. A. Ramai, H. Golzar and A. S. Kashani. 1995. Effectiveness of wheat yellow rust resistance genes in different part of Iran. Cereal Rusts Powdery Mildew Bull. 23: 9-12.

Yazdansepas, A., T. Najafi Mirak, S. Gholkari., M. Rezaie., Sh. Ashouri, M. Nazeri, M. Ghodsi, S. A. Razavi, M. Ezzat Ahmade and M. Chaichi. 2017a. Oroum, a new bread wheat cultivar for irrigated condition in cold regions of Iran. Seed Plant Improv. J. 27(3): 445-448.

Yazdansepas, A., M. Khodarahmi, M. Rezaie, M. Nazeri, A. Pedram, M. Chaichi, S. A. Razavi, A. R. Koocheki, T. Najafi Mirak and T. Babaie. 2017b. Zareh, a new bread wheat cultivar for irrigated and postanthesis drought stress conditions in cold regions of Iran. Seed Plant Improv. J. 27(4): 635-638.

Yazdansepas, A., A. Akbari, A. G. Sanjari, M. Rezaie, M. Chaichi, T. Babaie, G. Aminzadeh, A. Zareh Fayzabadi, M. Azzatahmadi and S. Ashouri. 2017c. Mihan, a new bread Wheat cultivar for irrigated and post-anthesis drought stress conditions in cold regions of Iran. Seed Plant Improv. J. 27(4): 631-634. 


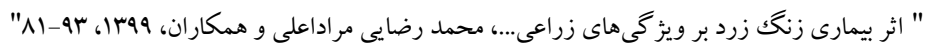

\title{
Effect of yellow rust disease on agronomic and physiological characteristics of winter and facultative bread wheat (Triticum aestivum L.) cultivars
}

\author{
Rezaei Moradali, M., ${ }^{1}$ A. R. Eivazi ${ }^{2}$ and Sh. Shir-Alizadeh ${ }^{3}$
}

\begin{abstract}
Rezaei Moradali, M., A. R. Eivazi and Sh. Shir-Alizadeh. 2020. Effect of yellow rust disease on agronomic and physiological characteristics of winter and facultative bread wheat (Triticum aestivum L.) cultivars. Iranian Journal of Crop Sciences. 22(1):
\end{abstract} 81-93. (In Persian).

To investigate the effect of yellow rust disease on some agronomic and physiological characteristics of bread wheat cultivars, two field experiments were conducted in Agricultural Research Station of Miandoab in West Azerbaijan, Iran, in 2013-2014 and 2014-2015 cropping seasons. Experimental treatments were arranged as factorial in randomized complete block design with three replications. Treatments included; non-sprayed and sprayed of Tilt fungicide with six winter and facultative bread wheat cultivars (Zarrin, Alvand, Pishgam, Oroum, Zareh and Mihan). Environmental conditions was inductive and yellow rust disease occured naturally in both cropping seasons. The results showed that Zarrin and Alvand cultivars had the highest disease infection $(63 \%$ and $57 \%$, respectively) in the non-sparyed treatment. However, Pishgam, Orum, Zareh and Mihan cultivars were resistant to yellow rust disease. Yellow rust decreased grain filling duration in sausceptible cultivars (Zarrin and Alvand) by 10 days. Leaf chlorophyll content of susceptible cultivars decreased in non-sprayed treatment from the milky to hard dough stage with a steepy slope. However, in the sprayed treatment leaf cholorophyll content decreased with slower rate. Yellow rust disease in non-sprayed treatment caused the highest proportion of reserved carbohydrtaes remobilization in Zarrin and Alvand by 30\%, but 1000 grain weight loss in susceptible cultivars was about $26 \%$. Despite of $29 \%$ increase in grain yield of susceptible cultivars in the sprayed treatment, the higher grain yield was obtained from resistant cultivars, Pishgham and Mihan (7877 and 7593 kg.ha-1, respectively). It can be concluded that integrated disease management by using resistant/ moderately resistant cultivars and fungicide application would be the best crop management practice to control yellow rust disease and reduce environmental pollution by application of less fungicide and reducing production costs.

Key words: Biotic stress, Bread wheat, Integrated disease management, Fungicide and Remobilization.

\footnotetext{
Received: June, $2019 \quad$ Accepted: December, 2019

1. Assistant Prof., Seed and Plant Improvement Research Department, West Azerbaijan Agricultural and Natural Resources Research and Education Center, Urmia, Iran (Corresponding author) (Email: Rezaei54@yahoo.com)

2. Assistant Prof., Seed and Plant Improvement Research Department, West Azerbaijan Agricultural and Natural Resources Research and Education Center, Urmia, Iran

3. Instructor, Seed and Plant Improvement Research Department, West Azerbaijan Agricultural and Natural Resources Research and Education Center, Urmia, Iran
} 